\title{
COPO MEIO CHEIO OU COPO MEIO VAZIO? ESTÁGIO PÓS-DOUTORAL, FACE EXPOSTA, REVISÃO CRÍTICA E AGENDA DE PESQUISA
}

\author{
Pedro Marcos Roma de Castro \\ Coordenação de Aperfeiçoamento de Pessoal de Nível Superior (CAPES) \\ Geciane Silveira Porto** \\ Universidade de São Paulo (USP)
}

RESUMO: Analisaram-se publicações sobre o tema da capacitação pósdoutoral nas bases Web of Science, Proquest, Scielo e Portal de Periódicos CAPES. De acordo com a revisão da literatura, o Brasil seria o possível agente de fronteira nesse campo investigativo. Apesar das amostras com organizações suniversitárias diversificadas, encontraram-se resultados similares entre elas, sendo que a variável tempo de carreira docente emerge como sendo o principal fator explicativo da transferência pós-doutoral positiva sobre a produção científica. Nesta revisão observa-se que, quanto ao marco teórico, todos os estudos convergiram para enxergar o fenômeno pós-doutoral à luz da Gestão do Conhecimento, e nesta revisão crítica, questionam-se os aspectos cruciais do ponto de vista teórico e metodológico para estudo do fenômeno pós-doutoral que devem ser objeto de reflexão visando a melhorias, mas há também uma visão otimista e promissora acerca desse campo de investigação, por ser um campo de exploração em pesquisa ainda escasso e com imenso potencial de desenvolvimento.

Palavras-chave: Estágio pós-doutoral. Produção científica. Gestão educacional.

http://dx.doi.org/10.1590/0102-4698140410

"Doutor em Ciências Sociais Aplicadas com ênfase em Administração, pela Universidade de São Paulo (USP). Analista em Ciência e Tecnologia Sênior da Coord. de Aperf. de Pessoal de Nível Superior (CAPES). Coordenador de Supervisão e Fomento da Universidade Aberta do Brasil (UAB). E-mail: pedro.castro@capes.gov.br.

" Doutora em Administração pela Universidade de São Paulo (USP). Professa Livre Docente da Faculdade de Economia, Administração e Contabilidade do campus de Ribeirão Preto da Universidade de São Paulo (FEA-USP/RP). E-mail: geciane@usp.br. 
IS THE CUP HALF FULL OR HALF EMPTY? POSTDOCTORAL RESEARCH, EXPOSED FACE, CRITICAL REVIEW AND RESEARCH SCHEDULE

ABSTRACT: Publications with the theme of post-doctoral training were analyzed, collected from the following databases:Web of Science, Proquest, Scielo and Portal de Periódicos CAPES.Results of literature review place Brazil as a possible border agent in this investigative field. Although the samples came from diverse academic organizations, similar results were found among them. The variable "teaching career time", emerges as the main explanatory factor to positive transfer to postdoctoral research about scientific production. Regarding theoretical framework of all studies reviewed, they converged, without exceptions,to focus postdoctoral research phenomenon with the Knowledge Management perspective. This critical review has questions about crucial aspects of a theoretical and methodological framework to study the phenomenon, we believethat it should be object of reflection for improvements. The paper also presents an optimistic view about this promising field of research, because it is afield of explorationin research, yet scarce and with great development potential. Keywords: Postdoctoral research. Scientific production. Educational management.

\section{INTRODUĈ̣̃O}

O pós-doutorado surge no cenário da pós-graduação na década de 90, como um item "extra" na carreira acadêmica, que, considerando o escalonamento atualmente existente, tem seu ponto máximo de exigência o título de doutorado. A ideia inicial é potencializar o uso dos recursos humanos e financeiros envolvidos diretamente com o cenário de produção e disseminação de ciência e tecnologia com vistas a ampliar a participação dos pesquisadores brasileiros no mainstream da ciência e facilitar sua inserção na comunidade científica internacional.

Nas universidades atualmente existe um crescente movimento de investimento em qualificação docente em nível de pós-doutorado que tem visado um melhor desempenho do conjunto sistêmico na sua missão de realizar ensino, pesquisa e extensão.Essa é uma tentativa de incrementar de forma constante o desenvolvimento científicotecnológico por meio da formação de recursos humanos, utilizando como instrumento os Pós-Doc, como são, nos nossos "corredores" da academia,chamados os estágios de pós-doutoramento.

Apesar da realização do pós-doutorado ser atualmente motivo de desejo de muitos doutores, por desenhar-se como um caminho atrativo e promissor, as atuais referências acerca do tema, como será abordado detalhadamente ao longo do artigo, mostram que o docente 
atuar em parceria com outros pesquisadores, com o objetivo centrado unicamente na busca do incremento na produção bibliográfica e no aumento dos "escores e linhas adicionais no Lattes" parece não ser uma estratégia líquida e certa. Há, no contexto do pós-doutorado, um caráter de formação e/ou atualização que vai além dessa perspectiva.

A visão neste artigo é a de que a capacitação via estágio pósdoutoral age como peça recente na engrenagem da pesquisa, opcional para a carreira acadêmica, mas que, no entanto, ganha grande destaque nos últimos anos, entre outras razões, dada a sua relevância para o conhecimento, o aprimoramento de competências, o aperfeiçoamento profissional e, de forma geral, a necessidade de atualização, como um todo.

Pesquisando-se em sites de revistas nacionais e também nas bases de dados: Web of Science, Pro Quest, Scielo e Portal de Periódicos da CAPES, buscou-se a literatura científica publicada em periódicos utilizando as palavras-chaves: postdoctoral research, sabbaticalstay, postdoctoral stage, post doctorate, postdoctoral training,capacitación postdoctorales,etapa de post-doctorado, post-doctorado, pós-doutorado, estágio pós-doutoral e treinamento pós-doutoral. Surpreendeu-nos a tamanha escassez de trabalhos sobre um assunto, em princípio, tão relevante, seja para a academia, para a área de gestão e fomento, para os aspectos da carreira docente, da capacitação e da formação do pesquisador ou para o desenvolvimento de políticas públicas de maneira mais ampla.

Todos os estudos encontrados são nacionais: não foram encontrados estudos elaborados no exterior e todos tiveram a linha de investigação na direção de uma aferição dos outputs do pósdoutorado. Neste campo investigativo encontram-se quatro artigos, o que mostra que a literatura científica expressa em mídia prestigiosa ainda é escassa e, por ser tão recente, também demonstra ser um campo de exploração em pesquisa, ainda raro, em fase exploratória e com imenso potencial de desenvolvimento.

O artigo de Castro e Porto(2008), publicado na revista Organizações e Sociedade, parece ser pioneiro, abrindo com êxito um campo de pesquisa até então não explorado. Castro e Porto(2010) e Calvosa, Repossi e Castro(2011) acabam seguindo a mesma linha desse primeiro paper, apresentando em seus trabalhos um mesmo "fio condutor" no que diz respeito às investigações empíricas, pois utilizam o mesmo método para a mensuração com pesos e ponderações para os diversos tipos de produção bibliográfica e analisam o fenômeno pósdoutoral à luz do referencial teórico da Gestão do Conhecimento. De comum em todos os artigos, há o balanço de que a atual conjuntura impulsiona a valorização dessa capacitação docente, o que confere relevância à análise do valor final dessa qualificação, estabelecendo motivação para a pesquisa e a busca de aferição dos seus resultados. 
Castro e Porto (2008) expõem uma realidade que chama a atenção: Quanto ao contexto pós-doutoral realizado no exterior, um docente que tenha realizado o doutorado pleno no exteriorapresenta resultados compatíveis e em "pé de igualdade" com docentes que possuam a experiência pós-doutoral como o primeiro contato tácito com a realidade da pesquisa realizada no exterior. Pinho (2008, p.10), ao debruçar-se sobre o tema do retorno ao exterior para estágios pósdoutorais, afirma que os "dados surpreendem ao indicar que os índices ocupam praticamente os mesmos patamares, bem como constatam ser válida a volta ao exterior para contato com pesquisadores estrangeiros".

Castro e Porto (2010), em continuidade dos estudos, indicam que, na realidade pós-doutoral, pelo menos nas hard sciencesda Universidade de São Paulo, não há heterogeneidade entre as áreas do conhecimento. Os autores chegam a essa conclusão após não encontrar diferenças significativas entre a produção dos pesquisadores antes e depois do pós-doutorado para as áreas de Biológicas, Engenharias, Exatas e da Terra e Saúde. Todas as áreas possuem resultados bastante semelhantes. Por sua vez, Calvosa,Repossi e Castro (2011) mergulham na questão do estágio pós-doutoral na Universidade Federal Fluminense- UFF, realizando um grande mapeamento do pós-doutorado nessa instituição e aferindo resultados em relação aos seus outputs (produção científica e bibliográfica).

Como principais resultados do estudo de Calvosa, Repossi e Castro (2011), corrobora-sea questão da não essencialidade exposta em Castro, Porto e Kannebley Jr. (2013) em relação à USP e demonstase que, na situação específica da UFF no Rio de Janeiro, há uma demanda praticamente igual entre os diversos estratos da carreira sênior, intermediário, recém-doutor - mas os resultados positivos do pós-doutorado são mais promissores para os pesquisadores seniores.

Como resultado da extensa pesquisa bibliográfica, uma questão que fica patente e chama a atenção é que, apesar da relevância do tema, há pouca diversidade em relação à autoria, sendo apenas cinco autores e coautores que trabalharam com a investigação do fenômeno e todos os (poucos) artigos encontrados na literatura sobre o tema em periódicos qualificados trabalham com a perspectiva da análise do fenômeno pós-doutoral sob a ótica da Capacitação para o Conhecimento ou da Gestão do Conhecimento.

\section{O PÓS-DOUTORADO À LUZ DA GESTÃO DO CONHECIMENTO}

O pós-doutorado surgiu recentemente no cenário da pósgraduação. O programa de estágio pós-doutoral foi criado pela Capes 
(Coordenação de Pessoal de Nível Superior) no ano de 1996 e, no ano de 2008, foi desmembrado em Pesquisa Pós-doutoral (para recém-doutores) e Estágio Sênior. A ideia da sua criação do programa foi potencializar o uso dos recursos humanos e financeiros envolvidos diretamente com o cenário de produção e disseminação da ciência, principalmente para fomentar tanto a fixação de doutores no Brasil, quanto a ampliação da participação dos pesquisadores brasileiros no mainstream da ciência e sua inserção na comunidade científica internacional.

Castro e Porto (2010) entendem o estágio pós-doutoral de professores com o objetivo de desenvolvimento de atividades de atualização, cooperação e abertura de novas linhas de pesquisa, sempre inseridas no contexto institucional de atuação do docente. Nessa ótica do pós-doutorado como um processo de interação entre universidades, pesquisadores são postos em contato com instituições relacionadas com o estado da arte de uma determinada área e pressupõe-se nesse processo a noção de complementaridade interorganizacional para o avanço do conhecimento científico.

Compartilhar éum dos benefícios amplamente reconhecidos pela gestão do conhecimento. Isso é bastante salientado por Powell (1998), no momento em que destaca que, em capacitação para o conhecimento, as redes interorganizacionais propiciam melhores resultados de inovação. A complementariedade a partir do compartilhamento de informações com outras organizações é evidenciada, também, por Nonaka e Takeuchi (1997) ao apresentarem a dimensão ontológica da criação do conhecimento. Diante dessa dimensão, o conhecimento nasce no nível individual, sendo expandido pela dinâmica da interação (socialização) e pela dinâmica da espiral do conhecimento.

O conhecimento para Nonaka e Takeuchi (1997) é subdividido em explícito e tácito. A criação do conhecimento inicia-se no nível do indivíduo, estendendo-se para o grupo e posteriormente para a instituição, podendo atingir níveis interorganizacionais. Essa interação é refletida no Modelode Conversão composto por: Socialização, Externalização, Combinação e Internalização. A socialização, ou disseminação, do tácito ocorre com experiências compartilhadas;não se trata de aprendizado por meio da linguagem, mas pela observação via contato social e prática. Pela externalização, o tácito é convertido em explícito, com a expressão geralmente de metáforas, códigos e analogias.

A combinação é a disseminação do explícito baseado na troca de codificáveis e, por meio da internalização, ou conversão do explícito em tácito, o conhecimento é incorporado às bases do indivíduo sob a influência do seu modelo mental e transformado em comportamento. Da integração dos quatro modos de conversão 
surge a espiral que se inicia no nível do indivíduo que, por meio da interação entre indivíduos, atinge gradativamente grupos, equipes, setores, organizações, áreas e redes.

Vistas como efeito do coletivo, há uma gama de unidades de conhecimento interrelacionadas que extrapolam a própria instituição e são geradas por conectividade com outras instituições, universidades ou instituições de pesquisa (ANTONELLI, 1999). Demonstrando que as instituições beneficiam-se da proximidade para buscar crescimento por meio de um processo de coevolução, ou seja, evolução com a produção de conhecimentos interrelacionados e complementares que extrapolam a própria organização, sendo gerados, no caso do pós-doutorado, por conectividade com outras universidades ou grupos de pesquisa.

FIGURA 1 - Espiral do Conhecimento e a questão pós-doutoral

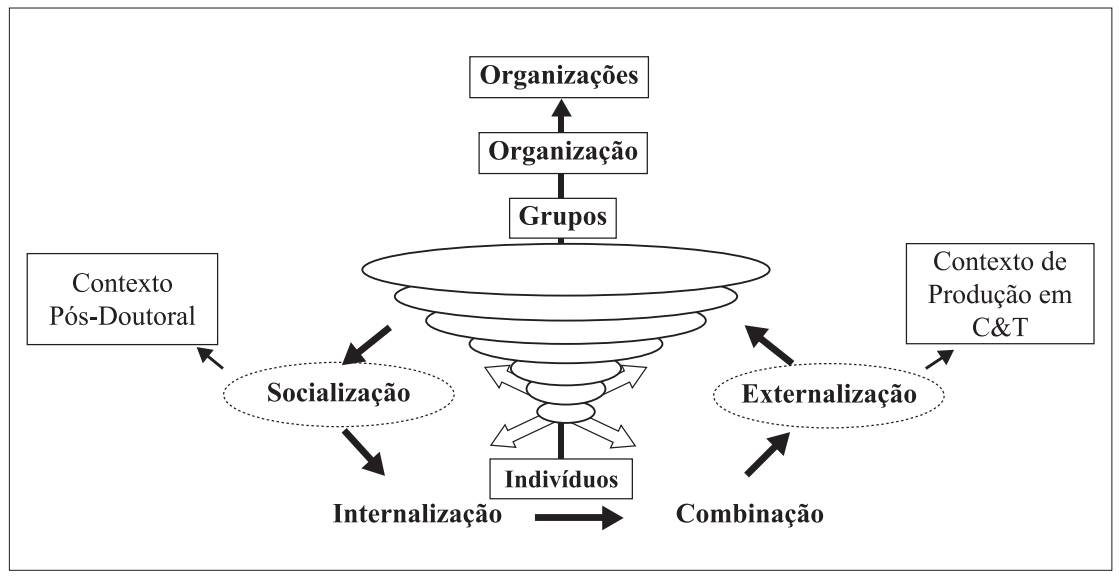

Fonte: CALVOSA; REPOSSI; CASTRO, 2011(adaptado).

Autores como Moody (2004) e Leydesdorff(2007) ressaltam o fato das relações sociais terem papel fundamental na construção do conhecimento científico. Nessa perspectiva da sociologia do conhecimento, enfatiza-se o fato de que o conhecimento científico é gerado socialmente, sendo intensificado por meio das interações, relações sociais e redes de colaboração.

O estágio pós-doutoral, além de pouco discutido, efetivamente constitui um fenômeno recente no próprio cenário acadêmico. Os poucos trabalhos existentes, como o de Castro e Porto (2008), e mais, recentemente, um segundo trabalho desses mesmos autores (CASTRO; PORTO, 2010) e o de Calvosa, Reposi e Castro(2011), interpretam o pós-doutorado à luz da Gestão do Conhecimento. 
Para esse conjunto de autores, concebendo-se o pós-doutorado como processo de interação, há a noção do pós-doc como um espaço em que se alternam condições de desenvolvimento e aquisição de conhecimentos, via práticas de outros laboratórios de pesquisa e de conectividade com outras práxis acadêmicas, sendo que, nesse processo de interação, se estabelecem situações de aprendizagem, por meio de conhecimentos eminentemente tácitos.

Nessainterseção entre organizações, universidades, laboratórios e projetos conjuntos, Popadiuk e Choo (2006) afirmam que a criação de conhecimento é essencialmente um compartilhamento de modelo mental, emocional e ativo para a agregação de valor. Nesse sentido, o processo criativo é também considerado um sistema social e as fontes de ampliação do conhecimento não residem exclusivamente dentro da organização, ao contrário, podem ser encontradas também nas redes e interações (POWELL, 1998; AJUHA, 2000).

O conhecimento científico explícito é codificado, facilmente estruturável e pode ser comunicado por sistemas estruturados ou meios formais de comunicação, compreendendo, então, todas as formas de literatura científica. O conhecimento científico tácito, por sua vez, refere-se ao que pode ser entendido como o conhecimento ou habilidade que pode ser passado entre cientistas por contatos pessoais, mas não pode ser exposto em fórmulas, diagramas, descrições verbais ou instruções para ação (LEITE; COSTA, 2007).

Para Leite e Costa (2007, p. 94), o tácito científico é o conhecimento baseado na informação científica que "contudo está relacionado com a experiência e a competência do pesquisador, portanto de difícil sistematização e representação. Diz respeito àquele conhecimento que é mais bem transferido e assimilado informalmente". Na procura de um modelo conceitual de gestão do conhecimento científico, os autores entendem que os sistemas informais exercem importante papel para a criação, o compartilhamento e o uso do conhecimento científico mesmo diante de meios mais formais de comunicação, como a exemplo das publicações, pois estas compartilham apenas ciência em sua vertente explícita.

O conhecimento científico pode ser explorado por meio de conhecimentos existentes que são de domínio individual, resultado de experiências pessoais e em interação com outras pessoas para formação de rede. Isso evidencia a importância de entender as relações e interações entre pesquisadores para se compreender estruturas cognitivas expressas nos textos científicos, uma vez que relações tácitas e padrões estruturados de conhecimento constituem fenômenos que são interligados (LEYDESDORFF, 2007). 
A 'ampliação' de conhecimentos surge quando, por meio da interação, o conhecimento eleva-se dinamicamente de um nível ontológico inferior até níveis mais altos. Nessa dimensão ontológica, observa-se que o conhecimento só é criado por indivíduos (NONAKA; TAKEUCHI, 1997). Uma rede interorganizacional, como é o caso que se estabelece no pós-doutorado, não pode criar conhecimentos, mas pode proporcionar um espaço de relações positivas e construtivas entre os pesquisadores. Assim, a partilha de informação, de opinião, de colaboração e de mobilização sobre um projeto confrontado com as necessidades e com o desconhecido converge para a 'ampliação' do conhecimento das universidades participantes.

Pela externalização, o conhecimento tácito é convertido em explícito. Dessa forma, o estágio pós-doutoral, de caráter eminentemente tácito, deveria convergir para novas produções científicas que possuam caráter explícito e possam ser compartilhados e disseminados pela comunidade acadêmica. Mas esse caminho não ocorre de forma tão direta e sem percalços.

"O que não foi dito precisa ser dito em voz alta; caso contrário, não pode ser examinado, aperfeiçoado ou compartilhado" (STEWART, 1998, p. 66). Os resultados obtidos no pós-doutorado que tem propósitos eminentemente de transferência de conhecimentos de fronteira por meio da Socialização - nos moldes de Nonaka e Takeuchi (1997) -, também não deveriam ficar restritos ao contexto da socialização, mas sim, ao sair do período de 'incubação', não ficar isolados, ampliando-se para os processos de externalização, para que possam vir a ser conhecidos pelos demais membros da comunidade científica.

O conhecimento explícito é formal e sistemático e, portanto, facilmente comunicado e compartilhadoe, no caso deinvestigação quantitativa, mais facilmente observável e mensurável. O conhecimento científico é racional e sistemático, desse modo, tendo-se em perspectiva o pós-doutorado como um processo que visa ao incremento do conhecimento - nesse caso em especial do conhecimento científico - até o momento os esforços de mensuração ocorreram em torno do externalizado, que se traduz no conhecimento cristalizado sob a forma de publicações científicas e que são compartilhadas pela comunidade acadêmica.

\section{GESTÃO DO CONHECIMENTOE PÓS-DOUTORADO: UMA UNIÃO COM ASPECTOS CRÍTICOS}

A Gestão do Conhecimento no Brasil ganhou grande força com a ampla divulgação da Teoria da Criação do Conhecimento 
de Nonaka e Takeuchi (1997), que considera quatro processos de conversão de conhecimento: socialização (tácito-tácito), externalização (tácito-explícito), combinação (explícito-explícito) e internalização (explícito-tácito). Primeiramente o conhecimento é socializado, depois externalizado e combinado em novos contextos para então ser internalizado, abrindo caminho para a geração permanente (Figura l).

A partir dos processos de conversão social, ou seja, de interações dinâmicas das pessoas, o conhecimento é criado e se expande em termos de qualidade e de quantidade através da organização, extrapolando níveis e fronteiras. Por meio da interação do tácito-explícito que formaas espirais ontológicas, a criação do conhecimento seria um "processo interminável que se atualiza continuamente" (NONAKA; TAKEUCHI, 1997, p.101).

Todavia, o sucesso obtido pela divulgação do livro de Nonaka e Takeuchi (1997) no ocidente não correspondeu à aplicação prática das proposições ali contidas, bem como, ao desenvolvimento do modelo universal de gerência proposto. Uma das críticas mais comuns, que é até reconhecida por um dos próprios autores, referese à dificuldade de operacionalizar a teoria no ambiente ocidental (GARVIN, 2001, KROGH; ICHIJO; NONAKA, 2001).

Em um artigo polêmico intitulado Why Nonaka highlights tacit knowledge: a critical review, Meng Li e Fei Gao (2003) procuram mostrar que o modelo proposto por Nonaka e Takeuchi é limitado se remetido ao conceito de original de Polanyi (1966), proposto na década de 50. A crítica aponta generalismo na atual ideia de externalização, pois nem todos os conhecimentos tácitos podem vir a ser codificados por meio do simbolismo da linguagem.

O argumento de Michael Polanyi (1966) diferencia implicitude de tacitude, ou seja, as capacidades ou potencialidades do conhecimento ser transferido e ensinado. O conhecimento tácito é aquele que não pode ser transferido,ele estaria arraigado nas práticas e formas particulares de agir e de conceber as coisas de cada pessoa. Nesse sentido, o tácito pode até vir a ser 'imitado', mas somente o conhecimento com implicitude potencial poderia ser trocado e compartilhado entre os indivíduos via externalização no futuro.

O pós-doutorado é visualizado como um local privilegiado para a complementaridade na formação de docentes altamente especializados e caracteriza uma situação de empreendimento coletivo. Uma das características no processo de partilha de conhecimento entre os pesquisadores, pelo menos no que concerne ao estágio pósdoutoral, é a qualidade eminentemente tácita em que ocorre a interação. Então, a primeira ressalva - obrigatória - é que há que se ponderar 


\section{que nem toda aprendizagem do estágio pós-doutoral poderá} vir a ser externalizada futuramente e transformada em publicações quando do retorno do pesquisador à instituição de origem.

O tácito ou o "implícito" transfere-se pela socialização, sendo que esta só é possível quando existe alguma proximidade. Como o conhecimento está nos indivíduos que interagem em um ambiente intra- e interorganizacional, a proximidade possibilita contato, socialização e criação de uma base comum de conhecimento. A transferência do implícito depende da proximidade que pode fornecer acesso às redes relacionais locais (COHENDET et al., 1999).

Nesse sentido, a lógica do pós-doutorado é incentivar essa proximidade visando o processo de desenvolvimento do conhecimento científico por meio da socialização entre pesquisadores em laboratórios de primeira linha e relacionados com a produção de fronteira, para assim a posteriori, por uma evolução do processo, por meio da externalização do conhecimento científico, culminar em uma produção para que possa vir a ser pública e compartilhada pelos demais membros da comunidade acadêmica (CASTRO; PORTO, 2008).

Entretanto, a crescente dependência do conhecimento científico deve ser vista com ressalva quando se considera a importância do conhecimento tácito para o processo de Ciência, Tecnologia e Inovação. O conhecimento científico é codificado e formalizado, podendo ser transferido por outros meios que não a socialização. Nesse sentido, ainda que a inovação esteja mais calcada no conhecimento científico, é importante esclarecer que o conhecimento tácito é relevante nos estágios iniciais do desenvolvimento, antes dos padrões terem sido estabelecidos e o design dominante ter sido fixado (DUNNING, 2000).

Estudos diversos vêm sendo desenvolvidos na tentativa de se elaborarem métodos de gestão desse ativo intangível. Hoje existe uma grande variedade de enfoques sobre o que se entende por Gestão do Conhecimento e estudos dedicados a confrontar compreensões e nuances entre elas. Hlupic, Pouloudi e Rzevski (2002), por exemplo, levantaram dezenove definições de Gestão do Conhecimento, classificando-as em dois grandes enfoques: aquelas que enfatizam as questões técnicas ( $h a r d$ ), e as que enfatizam questões humanas e organizacionais (soft). Terrett (1998), por sua vez, cita enfoques distintos, como aqueles que seguem as ideias de Gestão do Capital Intelectual (DAVENPORT; PRUSAK, 1998) e aqueles que seguem o sugerido por Nonaka e Takeuchi (1997).

Alazmi e Zairi (2003) revisaram a produção literária sobre a gestão do conhecimento, apontando uma síntese do abordado por quatorze autores sobre os fatores críticos de sucesso. Os fatores mais 
frequentes identificados são: comprometimento da alta gerência, comprome-timento de lideranças, cultura apoiadora, infra-estrutura tecnológica, estratégia e processos específicos para implementação. Além desses fatores, Alazmi e Zairi (2003) destacam que, em termos de recursos diretos, os autores revisados dão importância para as práticas de compartilhamento e para os investimentos para capacitar as pessoas (Sistema de T\&D - Treinamento e Desenvolvimento) para a sustentabilidade da gestão.

Nonaka e Takeuchi (1997) consideram, na gestão do conhecimento a influência de fatores como cultura e clima organizacional, incluindo estilos deliderança, políticas internas, sistemas de reconhecimento e recompensa, ambiente físico e das maneiras como o conhecimento é produzido e utilizado. Especificamente quanto às questões relativas aos fatores humanos, Krogh, Ichijo e Nonaka (2001) frisam a necessidade de se desenvolverem 'ativistas' do conhecimento, que ajudem a criar uma visão do conhecimento, elaborar contextos adequados para gestão, e que se esforcem em transformar o conhecimento localizado em organizacional. Ainda a respeito do fator humano, Stewart (1998) sugere que a organização deva preocupar-se em atrair e manter competências e dar as condições organizacionais para que essas competências possam interagir.

De uma forma polêmica, porém legítima e que abre espaço para discussão, Castro e Porto (2010) pontuam que no que tange à Gestão do Conhecimento, verifica-se que a mesma possui um arcabouço teórico emergente, nascido na turbulência dos anos 1990, representando uma abordagem com construtos recentes e em fase de grande ebulição de ideias e conceitos. A Gestão do Conhecimento representa um corpo teórico que ao longo de uma década tem sido fruto de intensos debates e de amadurecimento na busca de uma maior solidez teórica.

Entre os diversos autores que adotam o referencial da Gestão do Conhecimento em seus trabalhos, nota-se grande dispersão no que diz respeito ao seu escopo. A Gestão do Conhecimento relaciona-se com inteligência corporativa, memória organizacional, gestão de documentos, mapeamentodeprocessos, inovação,comunidadesdeprática, aprendizagem organizacional (LearningOrganizations), cultura organizacional, capital intelectual, tecnologia de informação e gestão de pessoas, apresentando grande amplitude e diversidade de enfoques(ALAZMI; ZAIRI, 2003, CASTRO; PORTO, 2010, DAVENPORT; PRUSAK, 1998, HLUPIC; POULOUDI; RZEVSKI, 2002, TERRET'T, 1998).

Nessa grande diversidade, os dois últimos enfoques Tecnologia de Informação e Recursos Humanos - são os que 
predominam na literatura da área, abarcando uma coleção de processos que têm a pretensão de gerenciar a criação, a disseminação e a utilização do conhecimento para atingir os objetivos estratégicos de uma organização. Entretanto, ao se olhar o referencial teórico da Gestão do Conhecimento, nota-se que não há, ainda, um equilíbrio entre considerar a importância da interface humana (múltiplos canais de contato para transferência e aprendizado) e a importância da interface propiciada pela Tecnologia de Informação, que abrange as tecnologias de hardwares, infraestrutura de redes, softwares, banco de dados, aplicações gerenciais, intranet, Internet e outros recursos computacionais e a interação entre as pessoas.

Krongh, Ichijo e Nonaka (2001, p.12), colocam que: “em muitas organizações, o interesse legítimo pela criação do conhecimento tem sido reduzido a um excesso de ênfase na tecnologia da informação". Esse enfoque, mesmo que considerado excessivo por alguns autores, ganha força visto que sistemas de informação estruturam-se em torno de uma grande base de dados central que envolve toda a corporação (DAVENPORT; PRUSAK, 1998) e passa a ser uma ferramenta com impacto na gestão à medida que compartilha e aproxima quem domina de quem necessita de determinados conhecimentos.

Essa divisão entre os entusiastas da gestão das tecnologias de informação e os entusiastas da gestão de pessoas, ambas relacionadas com a 'gestão' do conhecimento, no caso específico do pós-doutorado, possuium detalhe que merece ser considerado, especialmente se levarmos em consideração posições de autores como Dunning (2000), que argumentam que o conhecimento científico é codificado, formalizado e pode ser transferido por outros meios que não a socialização.

Essa relação entre Gestão de Tecnologia da Informação e Gestão de Pessoas mostra-se extremamente complexa e alimenta o embate comum na literatura da área de Gestão do Conhecimento. No caso do acesso ao conhecimento e da realização do pós-doutorado, esse conflito persiste, pois o acervo bibliográfico disponibilizado via Portal de Periódicos Capes passa por melhoras constantes, mas a demanda por realização de estágios pós-doutorais, especialmente no exterior, ao contrário de reduzir, tende a aumentar nos próximos anos, o que reforçaria a importância do contato humano nesse processo.

O Portal de Periódicos Capes ${ }^{1}$ é atualmente um Sistema de Informação que se traduz em uma importante ferramenta de pesquisa e em um instrumento fundamental para o desenvolvimento da pós-graduação nacional, permitindo o acesso on-line gratuito a um grande número de periódicos nacionais e internacionais para 
professores e estudantes de pós-graduação nas várias universidades. Sob a ótica da Gestão do Conhecimento, certamente o portal encontra-se mais voltado para a disseminação do conhecimento via Tecnologia da Informação, o que por sua vez tornaria mais fácil sua rápida atualização à distância e diminuiria, portanto, a necessidade de contatos presenciais e de socialização via pós-doutorado, para se ter contato com o estado da arte.

No que diz respeito às concepções imbutidas na Gestão do Conhecimento, diante de grande ebulição, uma questão que pode ser levantada na atualidade é se a Gestão do Conhecimento corresponderia a uma teoria em fase de evolução na busca de solidez, ou se a efervescência em torno da questão se constituiria em mais um modismo para a área da Administração. Obviamente, respostas para questões como essas não serão aparecerão de imediato e necessitarão do transcorrer do tempo e das próximas décadas para serem alcançadas.

A “exuberante" década de noventa assistiu, entre outros fenômenos, à transformação da gestão empresarial em religião new age, repleta de mantras como capital intelectual e gestão do conhecimento. Marcado desde o início por ambigüidades e cercado por polêmicas, o conceito de educação corporativa sobreviveu à primeira infância $\mathrm{e}$ ruma para o amadurecimento.(WOOD JR. $\left.{ }^{2}, 2004\right)$

Krongh, Ichijo e Nonaka (2001), logo no prefácio de sua obra, expõem de forma contundente: "estamos absolutamente convencidos de que não se gerencia o conhecimento, apenas capacitase para o conhecimento" (KRONGH; ICHIJO; NONAKA, 2001, p. 5) e acrescentam:

No entanto, embora seja fácil dizer "crie uma cultura que valorize o aprendizado"
ou discutir em termos gerais a economia baseada no conhecimento, os processos
humanos envolvidos - criatividade, diálogo, julgamento, ensino e aprendizado
- são de difícil mensuração. Com base no que sabemos sobre empresas
que enfrentaram essas questões, acreditamos que o conceito de gestão do
conhecimento em si seja limitado.(KRONGH; ICHIJO; NONAKA, 2001, p. 12)

Krongh, Ichijo e Nonaka (2001) assumem a inadequação do termo "gestão do conhecimento" em virtude de o termo gestão implicar em controle de processos que talvez sejam intrinsecamente incontroláveis. Os autores optam pela utilização da expressão capacitação para o conhecimento. Vale frisar que se está falando de (re)posicionamento, do próprio Nonaka, um dos nomes mais expressivos na área de gestão do conhecimento.

O sentido é de que a 'gestão' do conhecimento envolve ações de incentivo à produção do conhecimento, ao seu compartilhamento, 
a sua disseminação e a sua aplicação na solução de problemas e/ou na inovação. Essas ações de incentivo correspondem a práticas gerenciais de planejamento, organização e avaliação, ou seja, de incentivo à capacitação.

Diante das ponderações como as realizadas por Li e Gao (2003) e diante de recentes revisões de literatura como a de Rigo, Souza Filho e Souza (2007), que expõem que as ações de 'gestão' do conhecimento mais praticadas no Brasil são treinamento interno, treinamento e desenvolvimento externos, e-learning (uso da tecnologia da informação para promoção da aprendizagem), reuniões presenciais, cursos e a educação corporativa, ou seja, nada além das típicas técnicas de gestão de pessoas, fica a pergunta: para lançar luz no caso do pós-doutorado, que é uma atividade no sentido do aperfeiçoamento de pessoas, seria o referencial da gestão do conhecimento o único possível?

Li e Gao (2003) em suas constatações empíricas não chegaram a verificar empresas japonesas criando conhecimento, mas apenas transferindo conhecimento por meio de sistemas inteligentes e de um poderoso sistema de informação. Rigo, Souza Filho e Souza (2007) sustentam que, nos últimos anos, os entusiastas da gestão do conhecimento na área de Administração no Brasil começaram a atuar mais voltados para a gestão de pessoas, mas, por enquanto, não houve inovações nas práticas. Uma reflexão possível e que se estabelece então quase que de forma imediata é se a práxis tem sido coincidente com as práticas das áreas de Gestão de Recursos Humanos, Pedagogia, Andragogia, Psicologia Organizacional e, especialmente, com a área de Treinamento, Desenvolvimento e Educação. Não parece ser equívoco trilhar também caminhos consolidados em referenciais teóricos dessas áreas.

Há um dilema: Se, por um lado, grande parte das críticas dirigidas à Gestão do Conhecimento têm fundamento e devem ser objeto de reflexão consistente que preceda a formulação de proposições e planos de intervenção, por outro, nesse debate será indispensável reconhecer na identidade dos interlocutores suas intenções de dar a tônica de que o conhecimento é algo central na configuração da sociedade contemporânea.

Garvin (2001) sugere explicitamente algumas práticas que promovem a transferência de conhecimento cujos resultados são comprovados emutilizaçãoem grandes organizações. Entreessas práticas encontram-se relatórios, visitas às áreas de organização, transferência interna de pessoal para diversos pontos da organização, investimento em programas de educação, treinamento e desenvolvimento e práticas de incentivos adequados, pois, quando as pessoas sabem que seu aprendizado será reconhecido e aplicado, se tornam mais motivadas. 
Ao se considerar o pós-doutorado com propósitos de transferência de conhecimentos, informações, desenvolvimento de habilidades, desenvolvimento ou modificação de atitudes e desenvolvimento conceitual, verifica-se que ele se encontra incluído nas noções contemporâneas de Educação, Treinamento e de Desenvolvimento de recursos humanos-T,D\&E.

Nesse sentido, o pós-doutorado não é apenas um processo de incremento de conhecimento, mas de aprimoramento de competências do pesquisador/docente. Resgatando o termo "capacitação", ele encontra-se historicamente alinhado com a área de T\&D e, mais recentemente, com a emergente área da Educação em gestão de pessoas (BORGES-ANDRADE; ABBAD; MOURÃO, 2006), e, nesse contexto, o referencial teórico de $\mathrm{T} \& \mathrm{D}$ ou Educação nas corporações, ao trabalhar com competências que abrangem não apenas conhecimentos, mas Conhecimentos, Habilidades e Atitudes (CHAs), também pode fornecer subsídios e modelos adequados ao fenômeno do estágio pós-doutoral.

Pode-se ir além do referencial de T,D\&E - Treinamento, Desenvolvimento e Educação - nas organizações e no trabalho. Nada impede que se lancem caminhos elucidativos por diversas áreas que se envolvem nos aspectos da formação, da educação, do ensino e da pesquisa, no sentido de que as pesquisas acerca do pós-doutorado são atividades de avaliação. A avaliação, como prática educativa, deve ser também compreendida como atividade política, cuja principal função é de propiciar subsídios para tomadas de decisões quanto ao direcionamento das ações em um determinado contexto.

\section{A REVISÃO DOS ESTUDOS: PRINCIPAIS RESULTADOS, ASPECTOS POSITIVOS E AS NECESSÁRIAS RESSALVAS}

À luz da gestão do conhecimento e sob a perspectiva da produção científica, Castro e Porto (2008) abordam o pós-doutorado situando-se em uma região híbrida que abre espaço para uma situação onde se mesclam e se alternam condições de desenvolvimento e de aquisição de conhecimentos via práticas de outros laboratórios de pesquisa e conectividade com outras práxis acadêmicas. Para os autores, o pós-doutorado caracteriza um processo de interação e de socialização entre os pesquisadores em que se estabelecem situações de aprendizagem por meio de conhecimentos que são eminentemente tácitos, entretanto, espera-se que o processo possa convergir para novas produções científicas e tecnológicas que possuam caráter explícito. 
Os estudos posteriores (CASTRO; PORTO, 2010;CALVOSA; REPOSSI; CASTRO, 2011; CASTRO; PORTO; KANNEBLEY Jr., 2013,)seguem a essa mesma construção lógica no sentido de esperar-se que com o estágio pós-doutoral haja benefícios para a produção docente, bem como, impacto positivo para o programa de pós-graduação da instituição de origem. Com exceção de Castro, Porto e Kannebley Jr. (2013), as pesquisas analisaram a produção dos pesquisadores antes e depois da realização do pós-doutorado.

Castro, Porto e Kannebley Jr. (2013) não confrontaram o cenário antes e depois na produção do docente, mas seguiram outro caminho confrontando a produção dos docentes que fizeram pósdoutorado, com a produção dos docentes que não fizeram pósdoutorado, cotejando a produção com seus pares comparáveis, ou seja, os que concluíram o doutorado no mesmo ano, que atuam na mesma área e na mesma unidade da instituição, mas que realizaram ou não estágio pós-doutoral ao longo de sua carreira acadêmica.

Seguindo padrões nacionais, os estudos adotaram o critério Qualis para ter em consideração tanto a quantidade (número de publicações) como a qualidade. Esse critério expressa, pela base de avaliação CAPES, em princípio, a qualidade dos veículos de divulgação científica. Ao utilizar como parâmetro a ponderação via base Qualis, os estudos citados contaram com uma mensuração mais contextualizada para o cenário brasileiro. Os autores aproximaram-se em muitos aspectos de como as áreas realizam a avaliação dos seus programas de pós-graduação e ponderam a produção científica como um reflexo externalizado das atividades de pesquisa.

A ponderação proposta em Castro e Porto (2008) foi unanimemente utilizada nas investigações subsequentese teve por base o estabelecimento de uma pontuação para cada tipo de produção bibliográfica, indicadores construídos a partir das relações e ponderações aplicadas por diversas comissões de área. Foram dados a cada tipo de produção diversos "pesos", ou seja, para cada produção bibliográfica, foi associada determinada pontuação em função da importância e abrangência. O índice utilizado nos estudos, com a série de pontuações estabelecidas, reflete uma tendência e torna viável um cotejamento em amplitude.

Vale salientar que por mais que seja controverso, o maior e/ ou menor peso atribuído na composição equacionada via índice justifica-se pela própria natureza e identidade da pós-graduação stricto sensu. No país, o Qualis é utilizado por todas as áreas e, vale ressaltar que, a maneira como a fórmula foi estruturada não beneficiou e 
nem prejudicou a nenhuma das áreas do conhecimento. Assim, o ponto positivo das pesquisas foi demonstrar que, apesar da imensa diversidade e complexidade, é possível agrupar e analisar de forma conjunta a produção científica de uma forma ampla e ao mesmo tempo sintetizá-la sob a forma de um índice agregador de produção acadêmica em pesquisa. Isso implica, por exemplo, que não é necessário excluir determinadas produções para efetivar análises ou avaliações, mas apenas analisá-las com maior ou menor peso em função da sua importância para a comunidade acadêmica como um todo.

Desses mesmos método e qualidade dos estudos atuais, como uma dupla face, surge então uma importante ressalva: com a utilização do índice que pontua exclusivamente a produção bibliográfica, é indispensável reconhecer que ele abrange notadamente as atividades de pesquisa, mas é um fato que as atividades da pós-graduação não se restringem às atividades de pesquisa e, portanto, as dimensões do ensino e da extensão, presentes na pós-graduação, também poderiam ser merecedoras de uma atenção especial em estudos no futuro.

Mesmo considerando-se as atividades de publicação, há que se frisar que é urgente que o índice seja (re)adequado às novas realidades, especialmente no tocante à questão dos periódicos, tendo em vista que, para sua elaboração, há dois critérios básicos: a abrangência da circulação (Internacional, Nacional e Local) e os níveis de qualidade (A, B, C). Esses critérios foram fundidos e essa sistemática de classificação sofreu alterações por meio de um recente documento de caráter normativo CAPES/CTC (2009). Desde então os veículos periódicos de divulgação científica passaram a ser enquadrados em estratos indicativos da qualidade - desde o A1, o mais elevado, passando pelos seguintes: A2; B1; B2; B3; B4; B5, até C, o último nível.

Outra questão que merece destaque é que as pesquisas acerca da influência do pós-doutorado, ao optarem pela coleta por meio da base Lattes, ficaram restritas a uma fonte de dados secundários e,dessa forma,até o momento, osdocentes envolvidos no processo pós-doutoral não foram "ouvidos". Assim, as pessoas não se pronunciaram acerca de suas próprias percepções e avaliações e, dessa forma,os estudos deixaram à margem aspectos importantes, como: motivação, interesses, reações, satisfação com o estágio, visão de utilidade e de validade do estágio e a própria opinião dos envolvidos em relação à aprendizagem e à aplicação do pós-doc em outros campos que vão além da produção bibliográfica.

Com tantas ressalvas, não queremos deixar a impressão de que as nossas ponderações vão na direção de invalidar os resultados 
dos estudos atuais; pelo contrário, o índice de produção docente e a sua aplicação possuem seus méritos, entretanto, apenas é necessário frisar que as investigações com esses parâmetros possuem um escopo mais reduzido ou mais pontual e é necessário que seja ampliado e enriquecido. Mesmo assim, não há como negar, os trabalhos embrionários trazem à tona resultados reveladores que fazem emergir uma face inicial do estágio pós-doutoral.

Por exemplo, nessa fotografia exposta pelos estudos: Castro e Porto (2008) trazem importantes resultado sem dupla face: primeiramente surpreendem ao mostrar que, contrariando preconceitos iniciais sobre o tema, continua válido o retorno do pesquisador ao exterior, e, por fim, os resultados obtidos apontaram que o pós-doutorado realizado no Brasil apresenta resultados bem aquém do esperado, com menos retorno que os realizados no Exterior.

Cabe aqui, portanto uma ressalva, antes que se reforcem ideias como a de que não se produz mainstream da ciência no Brasil. Há que se fazer o registro de que o pós-doutorado, à luz da capacitação para o conhecimento, deveria ser um local privilegiado para ampliar-se a diversidade. Provavelmente há o aspecto da endogenia que não foi mensurada e que, talvez, seja crucial no que diz respeito ao baixo rendimento do pós-doutorado realizado no Brasil.

No estudo subsequente, Castro e Porto (2010, p.53) trazem a constatação de que a influência do pós-doutorado não é heterogênea entre áreas: "há uma variação média maior para a área de biológicas", mas essa variação não é da área como um todo; há uma grande dispersão e, em termos relativos, a influência do pós-doutorado mostra-se moderada e praticamente homogênea entre as grandes áreas do conhecimento. Pelos resultados, as áreas formam blocos com similaridades.

Calvosa, Repossi e Castro (2011) não tinham como objetivo entrar na discussão sobre se o pós-doc seria um item extra/opcional ou necessário/essencial na carreira docente, entretanto, com a finalidade de realizar um grande mapeamento do pós-doutorado na Universidade Federal Fluminense (UFF), o delineamento de pesquisa baseado no encontrado antes e depois do estágio pósdoutoral, entre outras coisas, também permitiu chegar à conclusão de que não é um item essencial para alavancar a carreira docente, mas sim um item opcional e importante para alguns docentes (não para todos). Os autores consideram que o pós-doc é capaz de impulsionar a produção científica tecnológica e contribuir de uma forma moderada para o avanço na carreira de pesquisador. 


\section{QUADRO 1}

Características das pesquisas sobre a influência do pós-doc sobre a produção em pesquisa

\begin{tabular}{|c|c|c|c|c|}
\hline Estudos & $\begin{array}{l}\text { Castro e Porto } \\
\text { (2008) }\end{array}$ & $\begin{array}{l}\text { Castro e Porto } \\
\text { (2010) }\end{array}$ & $\begin{array}{l}\text { Calvosa, Repossi e } \\
\text { Castro (2011) }\end{array}$ & $\begin{array}{l}\text { Castro, Porto e } \\
\text { Kannebley Júnior } \\
\text { (2013) }\end{array}$ \\
\hline $\begin{array}{c}\text { Mídia de } \\
\text { veiculação }\end{array}$ & $\begin{array}{l}\text { Organizações } \\
\text { \& Sociedade } \\
\text { (periódico). }\end{array}$ & $\begin{array}{c}\text { Revista de } \\
\text { Administração da } \\
\text { USP (periódico). }\end{array}$ & $\begin{array}{l}\text { Avaliação: Revista de } \\
\text { Avaliação da Educação } \\
\text { Superior (periódico). }\end{array}$ & $\begin{array}{l}\text { Avaliação: Revista de } \\
\text { Avaliação da Educação } \\
\text { Superior (periódico). }\end{array}$ \\
\hline $\begin{array}{c}\text { Organização } \\
\text { analisada }\end{array}$ & \multicolumn{2}{|c|}{ Universidade de São Paulo. } & $\begin{array}{l}\text { Universidade Federal } \\
\text { Fluminense }\end{array}$ & $\begin{array}{c}\text { Universidade de São } \\
\text { Paulo. }\end{array}$ \\
\hline Amostra & \multicolumn{2}{|c|}{$\begin{array}{l}\text { Não houve amostra - Nesses estudos } \\
\text { houve censo com um recorte focando } \\
\text { todos os doutores que realizam pós- } \\
\text { doutorado nas áreas de Biológicas, } \\
\text { Engenharias, Exatas e da Terra e Saúde. }\end{array}$} & $\begin{array}{l}\text { Não houve amostra, } \\
\text { estudo censitário em } \\
\text { toda a instituição } \\
\text { Fluminense. }\end{array}$ & $\begin{array}{l}\text { Amostra com } \\
\text { doutores com e } \\
\text { sem pós-doutorado, } \\
\text { atuantes nas áreas } \\
\text { de Biológicas, } \\
\text { Engenharias, Exatas e } \\
\text { da Terra e Saúde. }\end{array}$ \\
\hline Medida & \multicolumn{4}{|c|}{ Ponderação das publicações com base no índice de produção acadêmica em pesquisa. } \\
\hline $\begin{array}{l}\text { Tipo de } \\
\text { análise }\end{array}$ & $\begin{array}{l}\text { Comparação do } \\
\text { cenário ex ante } \\
\text { e ex post para o } \\
\text { mesmo docente. }\end{array}$ & $\begin{array}{l}\text { Comparação das } \\
\text { variações entre } \\
\text { grandes áreas do } \\
\text { conhecimento. }\end{array}$ & $\begin{array}{l}\text { Comparação do cenário } \\
\text { ex ante e ex post para } \\
\text { o mesmo docente. }\end{array}$ & $\begin{array}{l}\text { Delineamento } \\
\text { quase- experimental, } \\
\text { comparando a produção } \\
\text { de pesquisadores que } \\
\text { realizaram pós-doc } \\
\text { com a dos que não } \\
\text { realizaram }\end{array}$ \\
\hline $\begin{array}{c}\text { Referencial } \\
\text { teórico }\end{array}$ & \multicolumn{4}{|c|}{ Gestão do conhecimento. } \\
\hline $\begin{array}{l}\text { Fonte de } \\
\text { informação }\end{array}$ & \multicolumn{4}{|c|}{ Sistema Lattes } \\
\hline $\begin{array}{l}\text { Principais } \\
\text { resultados }\end{array}$ & $\begin{array}{l}\text { Continuou válido } \\
\text { o retorno ao } \\
\text { exterior, mesmo } \\
\text { para os docentes } \\
\text { que já haviam } \\
\text { concluído o } \\
\text { doutoramento } \\
\text { pleno no exterior. }\end{array}$ & $\begin{array}{l}\text { A influência do } \\
\text { pós-doutorado é } \\
\text { moderada. Não } \\
\text { há diferenças } \\
\text { significativas } \\
\text { entre áreas do } \\
\text { conhecimento } \\
\text { investigadas. }\end{array}$ & $\begin{array}{l}\text { A demanda pelo } \\
\text { pós-doc é igual nos } \\
\text { diversos níveis da } \\
\text { carreira, mas os } \\
\text { resultados são mais } \\
\text { promissores para os } \\
\text { seniores. Consideram } \\
\text { ser opcional, pois há } \\
\text { grande dispersão e } \\
\text { nem sempre o pós-doc } \\
\text { mostrou-se essencial } \\
\text { para alavancar a } \\
\text { produção científica. }\end{array}$ & $\begin{array}{l}\text { Concluem pelos dados } \\
\text { empíricos que o pós- } \\
\text { doutorado é opcional } \\
\text { para alavancar a } \\
\text { produção acadêmica. } \\
\text { Não é essencial, } \\
\text { pois vários doutores } \\
\text { conseguem ter boa } \\
\text { produção científica, } \\
\text { mesmo sem o ter } \\
\text { realizado. }\end{array}$ \\
\hline
\end{tabular}

Fonte: Elaborado pelos autores deste artigo. 
Além dessa consideração, Calvosa, Repossi e Castro (2011) trazem dados descritivos importantes, como os seguintes: (1) existe uma produção maciça em anais de eventos e praticamente nula em traduções, relevantes, por exemplo, para o ensino e a disseminação do conhecimento produzido; (2) na instituição investigada há baixa realização de pós-doutorado na área de agrárias; (3) de forma geral a procura pela realização de pós-doutorado foi praticamente homogênea e com mesma intensidade entre os recém-doutores, os intermediários e os seniores; e, talvez a informação mais relevante, (4) na UFF os resultados de influência do pós-doutorado sobre a produção bibliográfica são mais promissores para os pesquisadores seniores.

Como se observa no Quadro 1, o trabalho de Castro, Porto e Kannebley Júnior (2013) é o único artigo que foge do padrão estabelecido de comparação entre o antes e o depois. No trabalho, a investigação das possíveis influências do estágio pós-doutoral sobre o quantitativo da produção docente baseou-se na mensuração do desempenho de pesquisadores que realizaram estágio de pósdoutorado, confrontando-o com o desempenho de docentes que não realizaram (grupo de controle).

O artigo de Castro, Porto e Kannebley Jr. (2013) é bastante rico e com resultados expressivos. Em função do lastro empírico chegam a lançar luz sobre o dilema: a realização do pós-doutorado é essencial ou opcional? Para os autores, diante dos dados de influência encontrados, o pós-doutorado seria opcional. Afirmam isso em virtude de que todas as técnicas multivariadas empregadas não colocaram a situação de realização do pós-doutorado como sendo o principal agente de essencial influência sobre a produtividade docente.

A Figura 2, extraída de Castro, Porto e Kannebley Júnior (2013),demonstra que, em vários momentos, os docentes com pósdoutorados realizados possuem produção científica nos mesmos patamares ou até mesmo abaixo da produção dos pesquisadores que não realizaram pós-doutorado (linha constante ilustrada na figura - sendo mais visível essa relação nos pontos de 2, 5 e 9 anos após a obtenção do título de doutor) e isso aconteceu sistematicamente para os recémdoutores (considerados até cinco anos de conclusão do doutorado), entretanto, também ocorreu, em menor grau, com doutores seniores, sobre os quais os dados empíricos apontaram que os pares com e sem pós-doutorado, aos nove e aos dezesseis anos após a conclusão do doutorado, possuíam produção equivalentes. Ou seja, sendo o pósdoutorado não se mostra essencial para essa diferenciação na carreira. 
FIGURA 2 - Produção de docentes com pós-doutorado em relação aos seus pares sem pós-doutorado e a curva de estimação em potência que se aproxima dos dados empíricos encontrados na USP

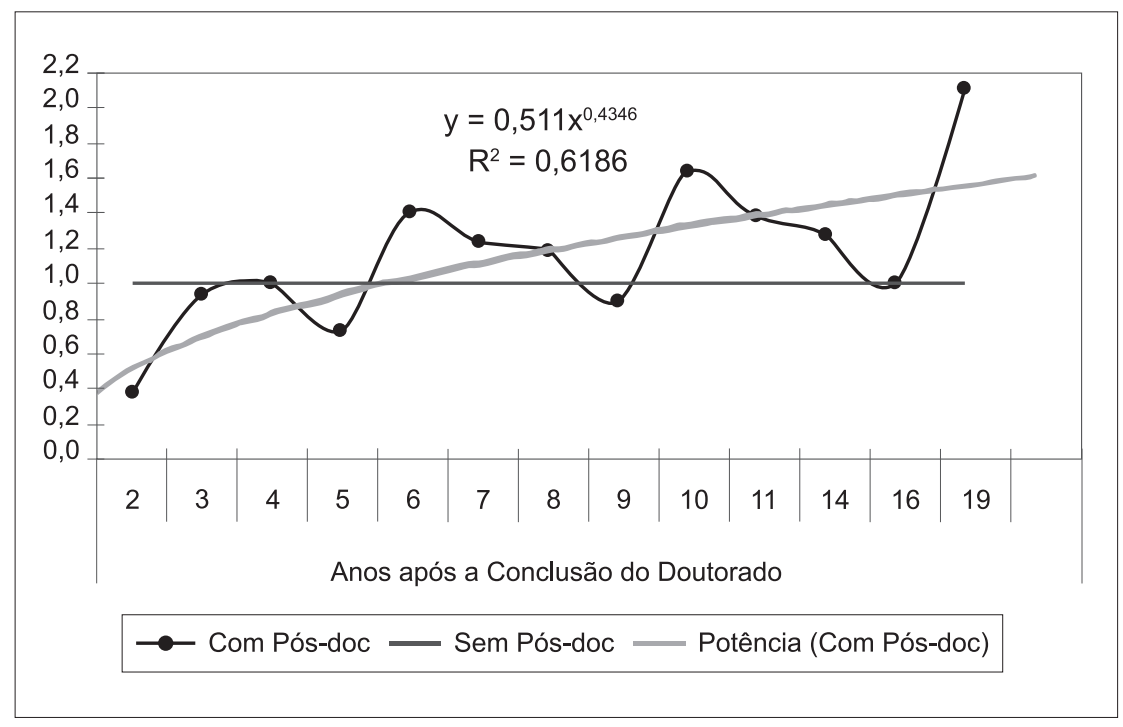

Fonte: CASTRO; PORTO; KANNEBLEY JR., 2013.

O Quadro1 sumariza as características das pesquisas discutidas nessa revisão. Observa-se principalmente uma convergência entre elas no que se refere ao referencial teórico, ao método e à opção de coleta por meio dos dados secundários com a utilização do sistema Lattes. Há ainda uma centralidade em relação à autoria e às organizações universitárias analisadas. Essa convergência não retira a força do material publicado, mas impulsiona as pesquisas futuras e outros autores, no sentido de que se arrisquem por outros caminhos em busca de respostas e avaliações cada vez mais aperfeiçoadas e precisas em relação a essa temática tão relevante para as políticas públicas e para a formação do pesquisador.

\section{CONSIDERAÇÕES FINAIS E UMA POSSÍVEL AGENDA DE PESQUISA EM RELAÇÃO AO FENÔMENO}

Perguntas tornam-se cruciais: Afinal, o pós-doutorado traz ou não retorno para o sistema de pós-graduação? É uma formação complementar válida? Vale a pena investir? Traz algum tipo de retorno? Essas respostas devem ser buscadas continuamente. A comunidade acadêmica provavelmente deverá resistir a certa ansiedade que pode 
se impor, pois, de certo, muitos estudos ainda serão necessários para termos respostas mais claras e/ou contundentes para essas questões.

Mas, se formos arriscar reunir todos os resultados das investigações em uma única frase, de forma sintética seria: a influência pós-doutoral é moderada, e os docentes que optaram por realizar o pós-doc no exterior e não imediatamente após a conclusão do doutorado tendem a apresentar resultados relativos superiores. Mas isso é um viés? É válido para o pós-doutorado no Brasil como um todo? Ou somente é condição própria da Universidade de São Paulo (USP) e da Universidade Federal Fluminense (UFF) que devem possuir suas particularidades e singularidades?

FIGURA 3 - llustração que suscita a reflexão: 0 copo encontra-se meio vazio ou meio cheio

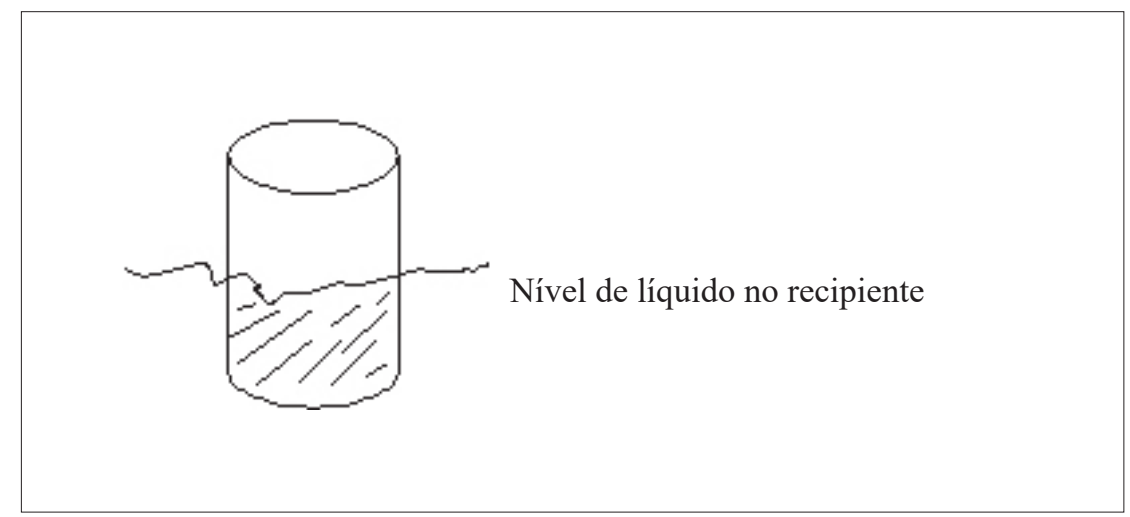

Fonte: Ilustração criada pelos autores.

A Figura 3 ilustra o clássico exemplo: copo meio cheio ou copo meio vazio... Diante de um recipiente com líquido até esse nível mediano, tudo gira em torno da perspectiva de quem observa. Em uma visão otimista é perfeitamente possível e há evidências para que se afirme que o recipiente está meio cheio, mas não há como fugir ad infinitum e em um tempo haverá que se registrar que o recipiente também está meio vazio. Essa dualidade posta meio cheio ou meio vazio torna-se certamente uma questão de interpretação crucial nessa situação da realização do estágio de pós-doutorado.

Assim, longe da pretensão de fornecer um ponto final para essa questão da influência sobrea produção científica ser forte ou fraca, sobre o "recipiente pós-doutoral" desenhado pelas pesquisas estar cheio ou vazio, o posicionamento dos autores neste artigo é que o estágio pós-doutoral pode configurar-se como um elemento opcional e importante que soma na questão da capacitação docente e 
no desenvolvimento, como formação complementar do pesquisador, e no sentido de que se coloque cada vez mais "gotas" nesse "copo" pós-doutoral para que ele se encha cada vez mais, fica a constatação de que o campo de pesquisa é vasto, promissor e para que maiores avanços possam ocorrer nessa área de avaliação é necessário:

- enriquecer o quadro em relação à autoria - ainda é pequeno o quantitativo do capital intelectual das nossas universidades interessado em investigar o fenômeno;

- ampliar e buscar integrar os dados de informações secundárias - via sistema Lattes -também com dados de fonte primária, buscando, dessa maneira,'ouvir' os docentes envolvidos que passaram pela vivência de um pós-doutorado na prática;

- reformular o índice de produção acadêmica para que ele possa adequar-se à reestruturação da base Qualis em pesquisa no tocante à nova avaliação dos periódicos;

- obter dados acerca de outras possíveis variáveis que possam estar interferindo no processo de influência do pós-doutorado sobre a produção na pós-graduação, como: aspectos gerais do suporte na instituição, reações favoráveis ou desfavoráveis dos docentes ao estágio realizado e, de uma forma mais ampla, a própria percepção de aprendizagem envolta nesse processo;

- ampliar o escopo acerca da produtividade, buscando trabalhar com perspectivas de influências em outras dimensões da produção docente na pós-graduação, como as atividades de ensino, orientação, produção de patentes, assessoria a órgãos de fomento e extensão;

- captar um maior número de instituições universitárias públicas e privadas, de outras regiões geográficas do país, de modo a garantir maior generalidade aos resultados;

- incluir na análise as variáveis referentes ao tempo de duração do estágio, o país de destino e a existência ou não de colaboração anterior entre os pesquisadores associados;

- aprofundar estudos buscando trabalhar não apenas com a média pontual, mas com um acompanhamento longitudinal, anual, e mais profundo no acompanhamento da produção científica dos doutores que realizaram e os que não realizaram o estágio pós-doutoral;

- visualizar o pós-doutorado como um processo não apenas de aquisição de conhecimentos, mas como um processo de aprimoramento de competências que envolvam o aprimoramento de conhecimentos, de habilidades e de atitudes relativas à função do docente-pesquisador. 
Para finalizar, é indispensável reconhecer que na busca constante da melhoria, no caso do pós-doutorado, há espaço para otimismo, e a ênfase nas pessoas é uma opção promissora. $\mathrm{O}$ foco restrito a aspectos financeiros, econômicos e/ou tecnológicos não seria suficiente para elucidar a dinâmica da ação universitária no sistema da pós-graduação. Um dos aspectos chaves para o aumento de produtividade é o investimento no fator humano:os docentes. Mas é preciso o sentido de que pesquisa traduz-se em outputs (livros, artigos...), e no tempo-espaço do trabalho não há separação do produto do ato humano de produção.

De forma geral, o que se pode afirmar é que, pelas pesquisas levantadas, o pós-doutorado situa-se em uma região intermediária no que se refere ao seu retorno ou seu resultado expost dobre a produção. A sua influência não é tão forte a ponto de ser principal diferencial e essencial para impulsionar a carreira ou a produção docente, mas, por outro lado, também se estabelece que a sua influência não é nula ou insignificante.

No momento, a julgar pelo estado da arte, há muito a se fazer. As avaliações e investigações são recentes e ainda há um longo caminho a percorrer em pesquisa. No entanto há resultados que fazem emergir inicialmente uma face pós-doutoral e esses resultados merecem todas as ressalvas e todos os senões apontados anteriormente, mas ao mesmo tempo são válidos e não apenas lançam respostas, como também, suscitam inúmeras questões a serem equacionadas.

\section{REFERÊNCIAS}

AJUHA, G. Collaboration networks, structural holes, and innovation: A longitudinal study. Administrative Science Quarterly, New York. v. 45, n. 3, p.425-455, sep. 2000.

ALAZAMI, N. E.; ZAIRI, K. Knowledge management critical success factors. Total Quality Management \& Business Excellence, Abingdon, v. 14, n. 2, p.199-205, 2003.

ANTONELLI, C. The evolution of the industrial organization of the production of knowledge Cambridge Journal of Economics, Oxford.v. 23, p. 243-260, 1999.

BORGES-ANDRADE, J. E.; ABBAD, G. S.; MOURÃO, L. Treinamento, Desenvolvimento e Educação em Organizações e Trabalho. Porto Alegre: Artmed/Bookman, 2006. 576p.

CALVOSA, M.V.D.; REPOSSI, M. G.; CASTRO, P. M. R. Avaliação de resultados da capacitação docente: $O$ pós-doutorado na Universidade Federal Fluminense sob a ótica da Produção Científica e Bibliográfica. Revista da Avaliação da Educação Superior, Campinas, v. 16, n. 1, p. 99-122, 2011.

CAPES/CTC. Reestruturação do Qualis. Brasília: [s. n.], 2009 Disponível em: <www.capes.gov. br/>. Acesso em: 15 dez. 2010. (Documento do Conselho Técnico Científico)

CASTRO, P. M. R.; PORTO, G. S. Retorno ao Exterior Vale a Pena? A questão dos estágios pós-doutorais sob a perspectiva da produção em C\&T. Organizações \& Sociedade, Salvador, v.15, n.47, p.155-173,2008. 
CASTRO, P. M. R.; PORTO, G. S.; KANNEBLEY JÚNIOR, S. Pós-doutorado, essencial ou ppcional? Revista da Avaliação da Educação Superior, Campinas, v. 18, n. 3, p. 773-801. 2013. CASTRO, P. M. R.; PORTO, G. S. Análise exploratória sobre avaliação e mensuração de resultados da capacitação via estágios pós-doutorais: heterogeneidade entre grandes áreas do conhecimento? Revista de Administração - RAUSP, São Paulo, v.45, n.1, p.43-56, 2010.

COHENDET, P. KERN, F.; MEHMANPAZIR, B.; MUNIER, F. Knowledge coordination, competence creation and integrated networks in globalised firms. Cambridge Journal of Economics, Oxford. v. 23, p. 225-241, 1999.

DUNNING, J. (Ed.) Regions, Globalization and the Knowledge Economy: the issues stated in regions, globalization and the knowledge-based economy. Oxford: University Press, 2000.

GARVIN, D. Gestão do conhecimento: construção da organização que aprende. Harvard Business Review Book, Rio de Janeiro: Campus, p. 50-81, 2001.

HLUPIC, V.; POULOUD, A.; RZEVSKI, G. Towards an integrated approach to knowledge management. Knowledge and Process Management, Nova Jersey, v. 9, n. 2, p. 90-102, apr./jun., 2002.

KROGH G.; ICHIJO, K.; NONAKA, I. Facilitando a criação do Conbecimento: reinventando a organização com poder de inovaşão contínua. São Paulo: Campus, 2001.

LEITE, F. C. L.; COSTA, S. M. S. Gestão do conhecimento científico. Ciência da Informação, Brasília, v. 36, n. 1, p. 92-107, 2007.

LEYDESDORFF, L. Scientific communication and cognitive codification: social systems and sociology of scientific knowledge. European Journal of Social Theory, Brighton, v. 10, n. 3, p. 1-22, 2007.

LI, M.; GAO, F. Why Nonaka highlights tacit knowledge: a critical review. Journal of Knowledge Management, Bradford,UK, v. 7, n.4, p.06-14, 2003.

MOODY, J. The structure of a social science collaboration network. American Sociological Review, Columbus, v. 69, n. 2, p. 213-239, 2004.

NONAKA, I; TAKEUCHI, H. Criação de conbecimentos na empresa: como as empresas japonesas geram a dinâmica da inovação. Rio de Janeiro: Campus. 1997.

PINHO, J. A. Apresentação - Editorial de abertura do n.47. Organizações \& Sociedade, Salvador, v. 15, n.47, p. 9-10, 2008.

POLANYI, M. The tacit dimension. London: Routledge e Kegan Paul, 1966.

POPADIUK, S.; CHOO, C. W. Innovation and knowledge creation: how are these concepts related? International journal of information management, Norfolk, v. 26, n. 4, p. 302-312, 2006.

POWELL, W. W. Learning from collaboration: knowledge and networks in the biotechnology and pharmaceutical industries. California Management Review, Berkeley, v. 40, p. 228-240, 1998.

RIGO, A. S.; SOUZA FILHO, N.A.; SOUZA, D. C. Gestão do Conhecimento: Aspectos críticos para a gestão de pessoas. Revista Adm.made, Rio de Janeiro,v.11, n. 2, p.47-70, 2007.

STEWART, T. A. Capital intelectual. Rio de Janeiro: Campus, 1998.

TERRETT, A. Knowledge management and the law firm. Journal of Knowledge Management. Bingley,UK, v. 2, n. 1, p. 67-77,1998.

\section{NOTAS}

${ }^{1}$ Disponível em: <www.periodicos.capes.gov.br> . Acesso em: 12/dezembro/2014.

${ }^{2}$ Transcrição de Thomaz Wood Jr. contida na capa /apresentação do Livro: Educação Corporativa no Brasil: mitos e verdades (EBOLI, Marisa, 2004). 
Recebido: 10/09/2014

Aprovado: 12/05/2015

Contato:

Pedro Marcos Roma de Castro QR 302 CONF 12 LT 09/10 Bloco A- Sl. 1103

Brasilia $|\mathrm{DF}|$ Brasil

CEP 72.300-653 